\section{OP40 ADVANCE CARE PLANNING IN MEDICAL TRAINING IN THE NETHERLANDS}

A Van der Plas*, R Pasman, W Westen. VUmc, Amsterdam, Netherlands

10.1136/spcare-2019-ACPICONGRESSABS.40

Our abstract is for a themed session and describes the workshop we want to give. In this workshop we will highlight the need to integrate ACP in the education of medical students and offer some examples of how to do this. Firstly, Judith Westen provides an introduction on the training needs of medical students and the current place of palliative care and ACP in the Dutch medical curricula. Then, Roeline Pasman discusses the outline of a minor on palliative care. She will illustrate the basic ingredients of the minor and show how ACP is integrated in the minor. Thirdly, in small groups, the participants of the workshop will experience different work forms that can be used to stimulate awareness of the need for ACP and train patient - physician communication regarding ACP (e.g discussion of a movie, role play, discussion on different communication styles). Afterwards the participants discuss their experiences and share ideas on how to integrate ACP in local training and education.

Target audience: Educators, healthcare professionals, researchers, policy makers.

Introduction and background palliative care and ACP in the curriculum of Dutch medical students

Example: Outline of a minor on palliative care

Interactive: working with training materials and role play

Group discussion: take home messages of participants

\section{OP41 ADVANCE CARE PLANNING AND PALLIATIVE CARE FOR HOMELESS PEOPLE IN MEDICAL RESPITE SHELTERS: A RETROSPECTIVE RECORD REVIEW}

S Van Dongen*, J Klop, B Onwuteaka-Philipsen, A De Veer, A Francke, M Slockers, I Van Laere, A van der Heide, J Rietjens. Erasmus MC, Rotterdam, Netherlands

\subsection{6/spcare-2019-ACPICONGRESSABS.41}

Background To improve advance care planning and palliative care for severely ill homeless people, insight into current practice is required. Therefore, the present study aims to describe the characteristics of people who deceased after having been homeless, the care preferred and received at the end of life, and difficulties in medical decision-making at medical respite shelters.

Methods We conducted a quantitative and qualitative retrospective record review at two Dutch medical respite shelters. Included were the medical and nursing records of 61 homeless clients who were known to be deceased between 2009 and 2016 and had resided in one of both shelters for at least one night in the three months before death.

Results The large majority of patients had a combination of somatic (98\%), psychiatric (85\%) and substance use problems (93\%). Discussions about imminent death were reported for $75 \%$ of the patients for whom it was recognized. Twenty-six percent of records provided information about patients' preferred place of death, which mostly was the shelter. For $36 \%$ of patients, hospital admissions had been considered undesirable by their clinician(s). In the three months before death, $75 \%$ of patients had at least one such admission. Documented difficulties in medical decision-making mainly concerned impaired decisional capacity of patients, language barriers, and fragmentation and discontinuity of care.

Conclusion At the end of life, homeless people suffer from multiple health-related problems that require specific expertise. They experience multiple, often undesired hospital admissions. This could be avoided by more comprehensive collaboration between psychosocial, medical, and palliative care.

\section{OP42 CONFRONTING VERSUS COMFORTABLE: TWO APPROACHES TO THE RECRUITMENT OF PEOPLE WITH LEARNING DISABILITY IN AN ADVANCE CARE PLANNING STUDY}

N McKenzie*, B Mirfin-Veitch, J Conder, H Trip. University of Otago, Christchurch, New Zealand

\subsection{6/spcare-2019-ACPICONGRESSABS.42}

Background Supporting people with learning disability to complete Advance Care Plans is relatively new and there is a lot to learn. This presentation discusses the recruitment processes and outcomes of two New Zealand based studies on this topic. The learnings from this may help us to increase the uptake of Advance Care Planning with people who have learning disabilities.

Methods Both studies are qualitative action research projects, both attempted to recruit 10 people with learning disability. A key difference is that the initial study recruited participants who were dying (and aware of that), while the current study recruited participants who were well. Recruitment data from both projects was analysed thematically to identify commonalities and differences in processes and outcomes.

Results Recruitment for the initial study was difficult, resulting in four participants. In contrast, recruitment for the current study was over-subscribed. Removing the need for participants to have a life-limiting condition contributed to this. In part this was because disability service staff, who sought expressions of interest for the study, were more comfortable to talking about Advance Care Planning within a pro-active context.

Conclusion Pro-active approaches to Advance Care Planning appear to be less confronting and more comfortable for disability staff. Taking a pro-active approach could increase uptake of Advance Care Planning for people with learning disability, who are clear that it is their right to plan for the end of their lives.

\section{OP43 THE APPLICATION OF SDM REGARDING PEOPLE WITH INTELLECTUAL DISABILITIESAS PART OF THE ACP PROCESS: A SCOPING REVIEW}

${ }^{1} \mathrm{HW}$ Noorlandt*, ${ }^{1} \mathrm{~A}$ van der Heide, ${ }^{2} \mathrm{MA}$ Echteld, ${ }^{1} \mathrm{IJ}$ Korfage. ${ }^{1}$ Erasmus MC, Rotterdam, Netherlands; ${ }^{2}$ Avans University of Applied Sciences, Breda, Netherlands

\subsection{6/spcare-2019-ACPICONGRESSABS.43}

Background Shared decision making (SDM) is the process in which the professional caregiver and patient (or the representative) both provide input and jointly discuss and decide which treatment policy will be followed. SDM is seen as an important component of the ACP process. Little is known about SDM in people with intellectual disabilities (ID). 